\title{
Space Vector Based Hybrid PWM Techniques for Reduced Current Ripple
}

\author{
G. Narayanan, Member, IEEE, Di Zhao, Harish K. Krishnamurthy, \\ Rajapandian Ayyanar, Senior Member, IEEE, and V. T. Ranganathan, Senior Member, IEEE
}

\begin{abstract}
This paper investigates certain novel switching sequences involving division of active vector time for space vectorbased pulsewidth modulation (PWM) generation for a voltage source inverter. This paper proposes two new sequences, and identifies all possible sequences, which result in the same average switching frequency as conventional space vector PWM (CSVPWM) at a given sampling frequency. This paper brings out a method for designing hybrid PWM techniques involving multiple sequences to reduce line current ripple. The three proposed hybrid PWM techniques (three-zone PWM, five-zone PWM and sevenzone PWM) employ three, five and seven different sequences, respectively, in every sector. Each sequence is employed in a spatial region within the sector where it results in the lowest rms current ripple over the given sampling period. The proposed techniques lead to a significant reduction in THD over CSVPWM at high line voltages. The five-zone technique results in the lowest THD among real-time techniques with uniform sampling, while the seven-zone technique is the best among real-time techniques with twin sampling rates. The superior harmonic performance of the proposed techniques over CSVPWM and existing bus-clamping PWM techniques is established theoretically as well as experimentally.
\end{abstract}

Index Terms-Harmonic analysis, harmonic distortion, hybrid PWM, induction motor drive, pulsewidth modulation (PWM), PWM inverters, space vector, space vector modulation, spread spectrum, stator flux ripple, switching sequences.

\section{INTRODUCTION}

$\mathbf{V}$ OLTAGE source inverter fed induction motors are widely used in variable speed applications. The harmonic distortion in the motor phase currents must be low for satisfactory operation of the motor drive. The harmonic distortion in the current is determined by the switching frequency and the pulsewidth modulation (PWM) technique employed. The switching frequency cannot be increased beyond a certain range due to practical limitations. Several efforts have been made to reduce the distortion at a given switching frequency by a good design of PWM technique [1]-[19].

Specially designed PWM techniques have been reported for high power applications [17]-[19] where the inverter switching

Manuscript received October 17, 2006; revised July 30, 2007. This work was supported by the U.S. Office of Naval Research (ONR) under Grants N0001402-1-0751 and N00014-05-1-0622. A preliminary version of the paper was presented at the IEEE Applied Power Electronics Conference (APEC), 2003.

G. Narayanan and V. T. Ranganathan are with the Indian Institute of Science, Bangalore 560 012, India.

D. Zhao is with Texas Instruments Incorporated, Dallas, TX 75243 USA.

H. K. Krishnamurthy and R. Ayyanar are with the Department of Electrical Engineering, Arizona State University, Tempe, AZ 85287 USA (e-mail: rayyanar@asu.edu).

Color versions of one or more of the figures in this paper are available online at http://ieeexplore.ieee.org.

Digital Object Identifier 10.1109/TIE.2007.907670 frequency is quite low [20]. For switching frequencies (say a few kilohertz) much higher than the maximum fundamental frequency (say 50 or $60 \mathrm{~Hz}$ ), several modulating functions [1]-[11] and frequency modulation of carrier [12] have been investigated. While stored waveform or off-line optimal PWM techniques result in good waveform quality [13]-[16], real-time PWM generation is necessary in many practical applications [10]. This paper focuses on developing and evaluating new realtime PWM techniques for voltage source inverters.

Sine-triangle PWM (SPWM) and conventional space vector PWM (CSVPWM) are popular real-time techniques [1]-[3]. CSVPWM and third harmonic injection PWM (THIPWM) lead to higher line side voltage for a given dc bus voltage compared to SPWM. These techniques also result in less harmonic distortion in the motor currents than SPWM at a given line voltage [1]-[3]. Discontinuous modulation methods lead to reduction in distortion at higher line voltages over CSVPWM for a given average switching frequency [1]-[9]. This paper proposes highperformance hybrid PWM techniques, which further reduce the distortion in line currents over comparable real-time PWM techniques at a given average switching frequency. The superiority in performance of the proposed techniques is established theoretically as well as experimentally.

With SPWM, CSVPWM and THIPWM, every phase switches once in a subcycle or a half-carrier cycle. This paper explores novel switching sequences that switch a phase twice in a subcycle, while switching the second phase once and clamping the third phase. This paper brings out all such possible sequences (including two new sequences), which result in the same average switching frequency as CSVPWM for a given sampling frequency.

Real-time PWM techniques balance the reference voltseconds and the applied volt-seconds over every subcycle or half-carrier cycle. The multiplicity of possible switching sequences provides a choice in the selection of switching sequence in every subcycle. The proposed hybrid PWM techniques employ the sequence, which results in the lowest rms current ripple over the given subcycle, out of a given set of sequences. Consequently, the total rms current ripple over a fundamental cycle is reduced.

Section II of this paper brings out the various possible switching sequences that can be employed in an arbitrary subcycle. Section III analyzes the rms current ripple over a subcycle due to different switching sequences. Section IV proposes three new hybrid PWM techniques. Section V evaluates the harmonic distortion due to the proposed techniques analytically, and shows that the proposed techniques lead to 


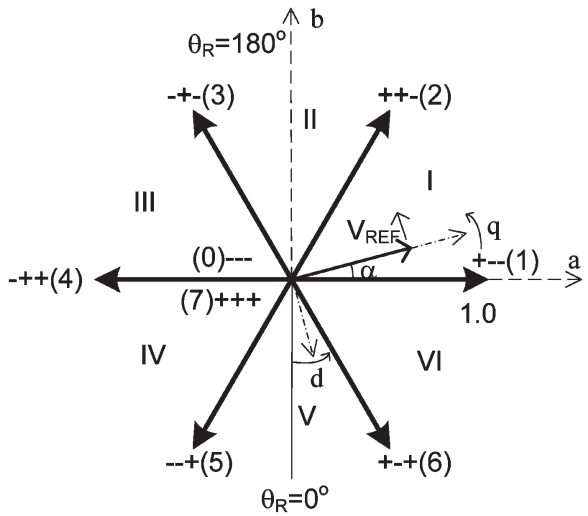

Fig. 1. Inverter states and voltage vectors. I, II, III, IV, V, and VI are sectors. $\theta_{\mathrm{R}}$ is angle of R-phase fundamental voltage.

reduced distortion over existing techniques at medium and high modulation indices. Section VI analyzes the inverter input current corresponding to the different PWM techniques. The theoretical predictions in Section $\mathrm{V}$ are validated through actual measurements in Section VII. The conclusions are presented in Section VIII.

\section{Switching SEQuences}

A three-phase voltage source inverter has eight switching states as shown in Fig. 1. The two zero states $(---$ and +++ ), which short the motor terminals, produce a voltage vector of zero magnitude as shown in the figure. The other six states, or the active states, produce an active voltage vector each. These active vectors divide the space vector plane into six sectors and are of equal magnitude as shown. The magnitudes are normalized with respect to the dc bus voltage $V_{\mathrm{dc}}$.

In space vector-based PWM, the voltage reference is provided by a revolving reference vector (see Fig. 1), which is sampled once in every subcycle, $T_{\mathrm{S}}$. Given a sampled reference vector of magnitude $V_{\mathrm{REF}}$ and angle $\alpha$ in sector I as shown in Fig. 1, the dwell times of active vector 1 , active vector 2 and zero vector in the subcycle are given by $T_{1}, T_{2}$, and $T_{\mathrm{Z}}$, respectively, in

$$
\begin{aligned}
T_{1} & =V_{\mathrm{REF}} \frac{\sin \left(60^{\circ}-\alpha\right)}{\sin \left(60^{\circ}\right)} T_{\mathrm{S}} \\
T_{2} & =V_{\mathrm{REF}} \frac{\sin (\alpha)}{\sin \left(60^{\circ}\right)} T_{\mathrm{S}} \\
T_{\mathrm{Z}} & =T_{\mathrm{S}}-T_{1}-T_{2} .
\end{aligned}
$$

CSVPWM divides $T_{\mathrm{Z}}$ equally between 0 and 7 , and employs the switching sequence $0-1-2-7$ or 7-2-1-0 in a subcycle in sector I. However, a multiplicity of sequences are possible since the zero vector can be applied either using 0 or 7 , and also an active state can be applied more than once in a subcycle [1], [17], [18], [21]-[23]. This paper explores and brings out all possible valid switching sequences, which have three switchings per subcycle as in CSVPWM. The conditions to be satisfied by a valid sequence in sector I are as follows.

1) The active state 1 and the active state 2 must be applied at least once in a subcycle.
2) Either the zero state 0 or the zero state 7 must be applied at least once in a subcycle.

3) In case of multiple application of an active state, the total duration for which the active state is applied in a subcycle must satisfy (1).

4) The total duration for which the zero vector (either using the zero state 0 or the zero state 7 ) is applied in a subcycle must satisfy (1).

5) Only one phase must switch for a state transition.

6) The total number of switchings in a subcycle must be less than or equal to three.

Conditions 1) to 4) ensure volt-second balance. Condition 5) avoids unwanted switchings to keep the switching losses low. Condition 6) ensures that the average switching frequency is less than or equal to that of CSVPWM for a given sampling frequency.

The applied inverter state is $0,1,2$, or 7 at any arbitrary instant in sector I. The state at the start of a subcycle, or the initial state, can be any of these four states. Considering 0 to be the initial state, all possible sequences satisfying conditions 1) to 6) are illustrated in Fig. 2(a). Only such sequences that result in exactly three switchings in a subcycle are considered in Fig. 2. Sequences 0121 and 0127 are valid sequences, while sequence 0101 is invalid since active state 2 never gets applied [violation of condition 1)]. Similarly, all possible sequences with 1,2 , and 7 as the initial states have been brought out in Fig. 2(b)-(d), respectively.

Totally ten valid sequences emerge from Fig. 2, which can be grouped into five pairs of sequences, namely $(0127,7210)$, (0121, 1210), (1012, 2101), (2721, 1272), and (7212, 2127). CSVPWM uses the pair of conventional sequences (0127, 7210) in alternate subcycles in sector I. The other four pairs can also be employed in alternate subcycles in sector I. These four pairs of sequences are termed as "special sequences," since these result in double-switching of a phase, single switching of another phase and clamping of the third phase in the given subcycle. In special sequences of type I, there are two transitions between the active states 1 and 2 . In special sequences of type II, there are two transitions between an active state and the zero state closer to it (i.e., between 1 and 0 or between 2 and 7).

Further there are also valid sequences with only two switchings, namely $012,210,721,127$. Sequence 012 , for instance, can be viewed as a special case of 0127, 0121, or 1012 . Similarly, the other two-switching sequences can also be seen as special cases of certain three-switching sequences. These sequences are termed "clamping sequences," and are employed by discontinuous modulation methods [1]-[10]. Sequences 012 and 210 or sequences 721 and 127 can be used in alternate subcycles in sector I.

All the above sequences pertain to sector I. Sequences pertaining to the other sectors are listed in Table I.

Of every pair of sequences, just one can be taken as a representative. Hence, there are seven sequences as illustrated in Fig. 3. While conventional and clamping sequences have been studied extensively [1]-[11], the special sequences have received only limited attention [1], [17], [18], [21]-[23]. All seven sequences are analyzed and compared from the point of view of current ripple in the following section. 
(a)

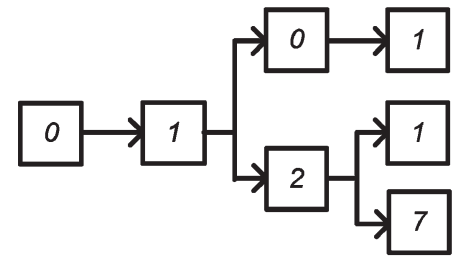

Invalid since state 2

is not applied

Sequence 0121

Sequence 0127

(b)

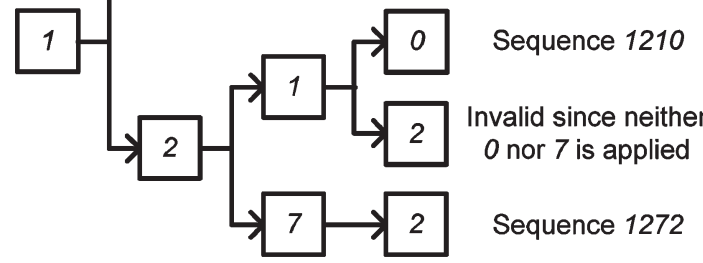

(c)

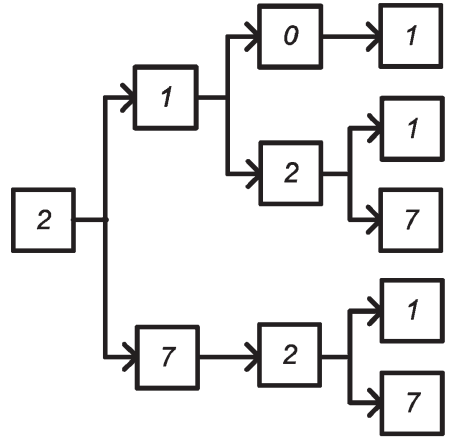

Sequence 2101

Invalid since neither

0 nor 7 is applied

Sequence 2127

Sequence 2721

(d)

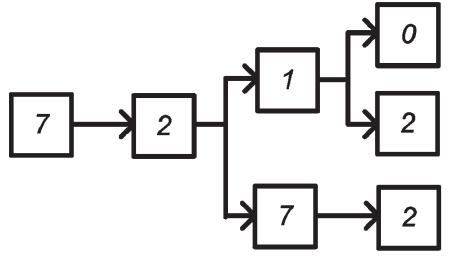

Invalid since state 1 is not applied

Sequence 7210

Sequence 7212

Invalid since state 1 is not applied

Fig. 2. Valid sequences for initial state (a) 0 , (b) 1 , (c) 2, and (d) 7 .

TABLE I

Switching SEQuences in Six SECTORS

\begin{tabular}{|c|c|c|c|c|}
\hline Sector & $\begin{array}{c}\text { Conventional } \\
\text { sequence }\end{array}$ & $\begin{array}{c}\text { Clamping } \\
\text { sequences }\end{array}$ & $\begin{array}{c}\text { Special } \\
\text { sequence type I }\end{array}$ & $\begin{array}{c}\text { Special } \\
\text { sequence type II }\end{array}$ \\
\hline I & $(0127,7210)$ & $\begin{array}{c}(012,210), \\
(721,127)\end{array}$ & $\begin{array}{c}(0121,1210), \\
(7212,2127)\end{array}$ & $\begin{array}{c}(1012,2101), \\
(2721,1272)\end{array}$ \\
\hline II & $(7230,0327)$ & $\begin{array}{c}(723,327), \\
(032,230)\end{array}$ & $\begin{array}{c}(7232,2327), \\
(0323,3230)\end{array}$ & $\begin{array}{c}(2723,3272), \\
(3032,2303)\end{array}$ \\
\hline III & $(0347,7430)$ & $\begin{array}{c}(034,430), \\
(743,347)\end{array}$ & $\begin{array}{c}(0343,3430), \\
(7434,4347)\end{array}$ & $\begin{array}{c}(3034,4303), \\
(4743,3474)\end{array}$ \\
\hline IV & $(7450,0547)$ & $\begin{array}{c}(745,547), \\
(054,450)\end{array}$ & $\begin{array}{c}(7454,4547), \\
(0545,5450)\end{array}$ & $\begin{array}{c}(4745,5474), \\
(5054,4505)\end{array}$ \\
\hline V & $(0567,7650)$ & $\begin{array}{c}(056,650), \\
(765,567)\end{array}$ & $\begin{array}{c}(0565,5650), \\
(7656,6567)\end{array}$ & $\begin{array}{c}(5056,6505), \\
(6765,5676)\end{array}$ \\
\hline VI & $(7610,0167)$ & $\begin{array}{c}(761,167), \\
(016,610)\end{array}$ & $\begin{array}{c}(7616,6167), \\
(0161,1610)\end{array}$ & $\begin{array}{c}(6761,1676), \\
(1016,6101)\end{array}$ \\
\hline
\end{tabular}

\section{Analysis of CURREnt RipPle in a Subcycle}

In a PWM inverter fed induction motor drive, there is an error between the instantaneous applied voltage vector and the reference voltage vector. For a given reference vector in sector I, the error voltage vectors corresponding to the active (a)



(b)

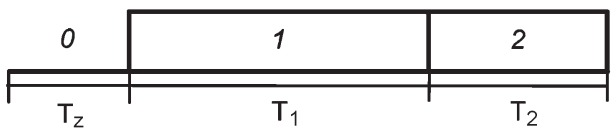

(c)

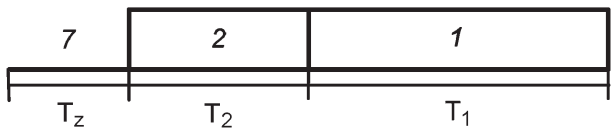

(d)

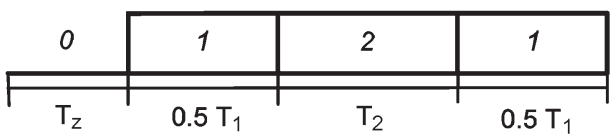

(e)

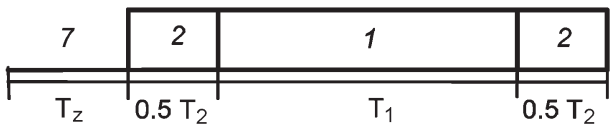

(f)

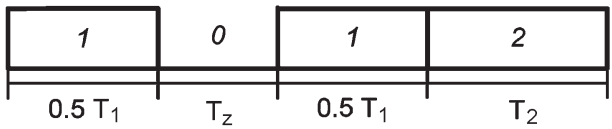

(g)

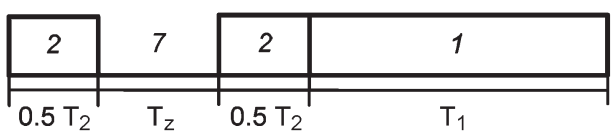

Fig. 3. Possible switching sequences in sector I (a) 0127, (b) 012, (c) 721, (d) 0121, (e) 7212, (f) 1012, and (g) 2721.

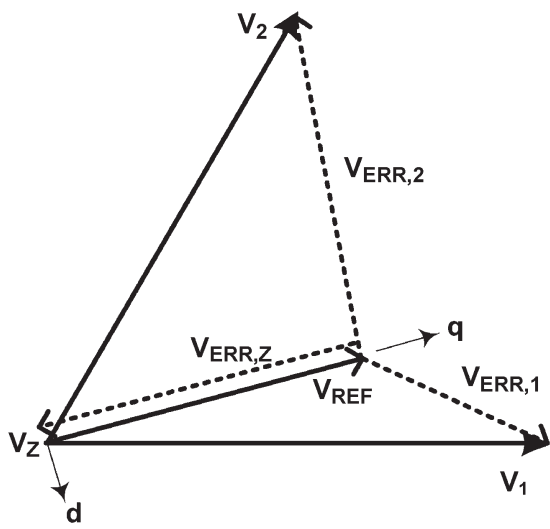

Fig. 4. Error voltage vectors corresponding to active vector 1, active vector 2, and zero vector.

vector 1 , the active vector 2 and the zero vector are as illustrated in Fig. 4, and as expressed in

$$
\begin{aligned}
\mathbf{V}_{\text {ERR,1 }} & =\mathbf{V}_{1}-\mathbf{V}_{\text {REF }} \\
\mathbf{V}_{\text {ERR,2 }} & =\mathbf{V}_{2}-\mathbf{V}_{\text {REF }} \\
\mathbf{V}_{\text {ERR,Z }} & =-\mathbf{V}_{\text {REF }} .
\end{aligned}
$$

The time integral of the error voltage vector is termed here as the "stator flux ripple vector." This is a measure of the ripple in the line currents of the converter. In particular, the 
Trajectory

(a)

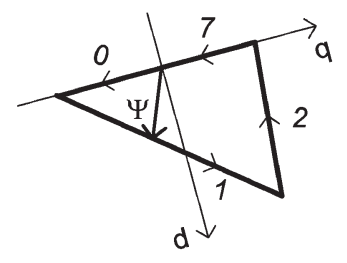

(b)

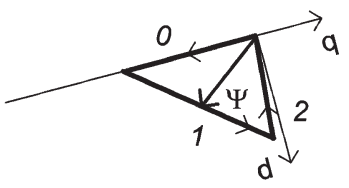

(c)

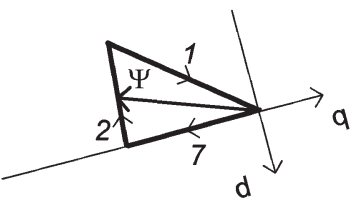

(d)

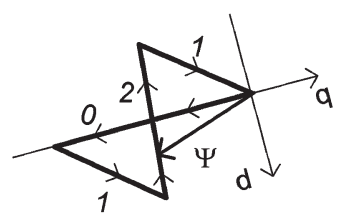

(e)

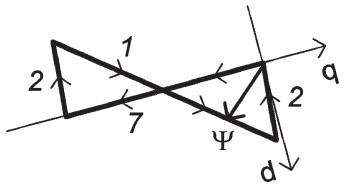

(f)

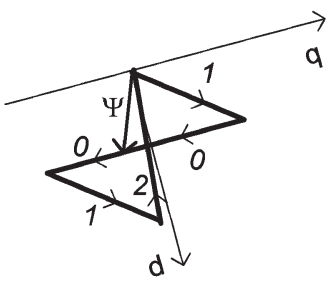

(g)

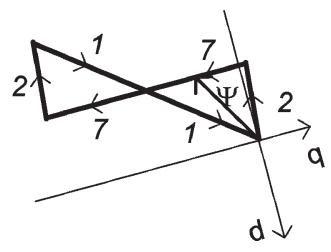

$q$ - axis ripple
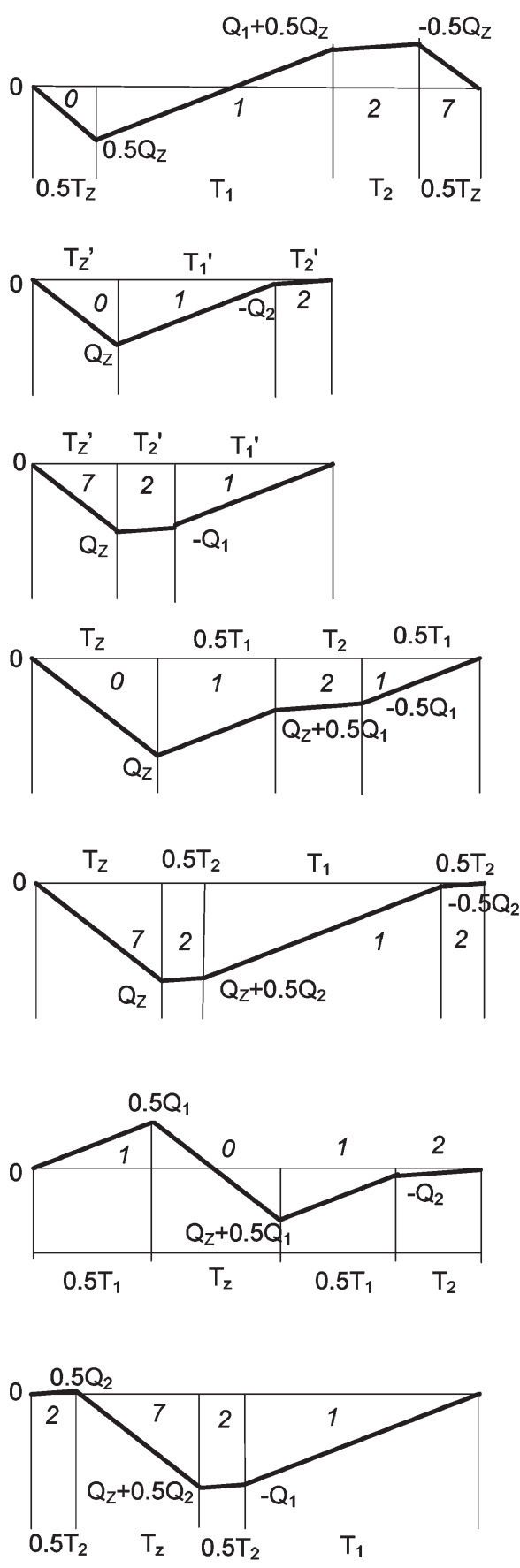

d - axis ripple
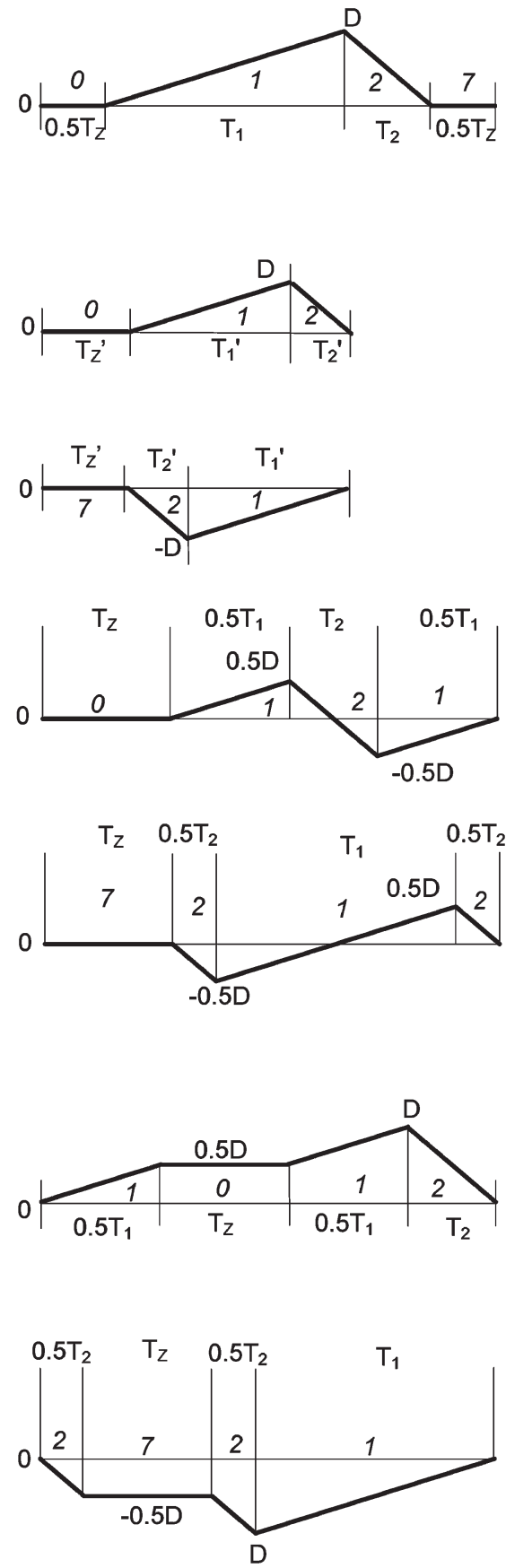

Fig. 5. Stator flux ripple vector over a subcycle for sequences (a) 0127, (b) 012, (c) 721, (d) 0121, (e) 7212, (f) 1012, and (g) 2721

rms value of stator flux ripple over a subcycle is a measure of the rms current ripple over the given subcycle [7]-[9], [17], [18], [23]. The purpose of this paper is to study the rms ripple over a subcycle due to different sequences, and utilize this knowledge to design hybrid PWM techniques, which use the most appropriate sequence in every subcycle so as to reduce the line current distortion.

Fig. 5(a)-(g) illustrates the stator flux ripple vector over a subcycle corresponding to the seven sequences for a given reference vector $\left(V_{\mathrm{REF}}=0.65, \alpha=15^{\circ}\right)$. Since sequences 012 and 721 have only two switchings per subcycle, a subcycle duration $T_{\mathrm{S}}=(2 T / 3)$ is considered for these two sequences, while $T_{\mathrm{S}}=T$ for the other sequences. This ensures comparison of sequences at the same average switching frequency, $f_{\mathrm{sw}}$. The stator flux ripple vector can be resolved along $d$-axis and $q$-axis, which are the reference axes of a synchronously revolving reference frame, as shown in Fig. 5. The $q$-axis is aligned with the reference voltage vector $\mathbf{V}_{\mathbf{R E F}}$, and the $d$-axis lags behind the $q$-axis by $90^{\circ}$ as shown.

The error volt-second quantities $Q_{\mathrm{z}}, Q_{1}, Q_{2}$, and $D$ in Fig. 5 are as defined in (3). These are products of a component of the error voltage vector (say along $q$-axis) corresponding to a 
given applied voltage vector (say $\mathbf{V}_{1}$ ) and the dwell time of the applied vector (say $T_{1}$ )

$$
\begin{aligned}
Q_{1} & =\left[\cos (\alpha)-V_{\mathrm{REF}}\right] T_{1} \\
Q_{2} & =\left[\cos \left(60^{\circ}-\alpha\right)-V_{\mathrm{REF}}\right] T_{2} \\
Q_{\mathrm{Z}} & =-V_{\mathrm{REF}} T_{\mathrm{Z}} \\
D & =\sin (\alpha) T_{1} .
\end{aligned}
$$

In all cases, the magnitude of the stator flux ripple vector is zero at the start as well as the end of the subcycle. The tip of the stator flux ripple vector moves parallel to the instantaneous error voltage vector during the subcycle. For sequences 0127 , 012 , and 721 , the trajectory of the tip of the stator flux ripple vector is triangular as shown in Fig. 5(a)-(c). Since the subcycle duration for 012 and 721 is only two thirds that of 0127 , the sides of the triangles are correspondingly shorter. As seen from Fig. 5(d)- $(\mathrm{g})$, the trajectory of the tip of the ripple vector is "double-triangular" for the special sequences.

\section{A. Expressions for RMS Current Ripple}

For all sequences, the $q$-axis and the $d$-axis stator flux ripple are continuous and piecewise linear functions of time. The slope of the function changes at the switching instants. The $q$-axis ripple for 0127, for example, has four linear sections as seen from Fig. 5(a). The square of this function has four corresponding parabolic sections. The mean square $q$-axis ripple can easily be obtained by summing the areas under these four parabolic sections [see the first four terms in the right-hand side (RHS) of (4a)]. The mean square $d$-axis ripple can also be computed in a similar fashion [see the last term in RHS of (4a)]. The total mean square stator flux ripple over a subcycle is the sum of mean square values of the $q$-axis ripple and the $d$-axis ripple as shown in (4a) [18], [23].

Expressions for the rms stator flux ripple over a subcycle for sequences $012,721,0121$, and 7212 (i.e., $F_{012}, F_{721}, F_{0121}$, and $F_{7212}$ ) have also been derived along similar lines from Fig. 5(b)-(e), respectively [18], [23]. The respective expressions are in (4b)-(4e).

The rms ripple over a subcycle corresponding to the new sequences 1012 and 2721, namely $F_{1012}$ and $F_{2721}$, are computed here following a similar approach. The rms value is expressed in terms of the values of the $q$-axis ripple and $d$-axis ripple at the switching instants as shown in 4(f) and 4(g).

$$
\begin{aligned}
F_{0127}^{2}= & \frac{1}{3}\left(0.5 Q_{\mathrm{Z}}\right)^{2} \frac{T_{\mathrm{Z}}}{2 T}+\frac{1}{3} \\
& \times\left[\left(0.5 Q_{\mathrm{Z}}\right)^{2}+0.5 Q_{\mathrm{Z}}\left(0.5 Q_{\mathrm{Z}}+Q_{1}\right)+\left(0.5 Q_{\mathrm{Z}}+Q_{1}\right)^{2}\right] \\
\times & \frac{T_{1}}{T}+\frac{1}{3}\left[\left(0.5 Q_{\mathrm{Z}}+Q_{1}\right)^{2}-\left(0.5 Q_{\mathrm{Z}}+Q_{1}\right)\right. \\
& \left.\times 0.5 Q_{\mathrm{Z}}+\left(-0.5 Q_{\mathrm{Z}}\right)^{2}\right] \\
& \times \frac{T_{2}}{T}+\frac{1}{3}\left(-0.5 Q_{\mathrm{Z}}\right)^{2} \frac{T_{\mathrm{Z}}}{2 T}+\frac{1}{3} D^{2} \frac{\left(T_{1}+T_{2}\right)}{T}
\end{aligned}
$$

$$
\begin{aligned}
F_{012}^{2}= & \frac{4}{27} Q_{\mathrm{Z}}^{2} \frac{T_{\mathrm{Z}}}{T}+\frac{4}{27} \\
& \times\left[Q_{\mathrm{Z}}^{2}+Q_{\mathrm{Z}}\left(Q_{\mathrm{Z}}+Q_{1}\right)+\left(Q_{\mathrm{Z}}+Q_{1}\right)^{2}\right] \\
& \times \frac{T_{1}}{T}+\frac{4}{27}\left[\left(Q_{\mathrm{Z}}+Q_{1}\right)^{2}\right] \frac{T_{2}}{T}+\frac{4}{27} D^{2} \frac{\left(T_{1}+T_{2}\right)}{T} \quad(4 \mathrm{~b}) \\
F_{721}^{2}= & \frac{4}{27} Q_{\mathrm{Z}}^{2} \frac{T_{\mathrm{Z}}}{T}+\frac{4}{27} \\
& \times\left[Q_{\mathrm{Z}}^{2}+Q_{\mathrm{Z}}\left(Q_{\mathrm{Z}}+Q_{2}\right)+\left(Q_{\mathrm{Z}}+Q_{2}\right)^{2}\right] \\
& \times \frac{T_{2}}{T}+\frac{4}{27}\left[\left(Q_{\mathrm{Z}}+Q_{2}\right)^{2}\right] \frac{T_{1}}{T}+\frac{4}{27} D^{2} \frac{\left(T_{1}+T_{2}\right)}{T} \\
F_{0121}^{2}= & \frac{1}{3} Q_{\mathrm{Z}}^{2} \frac{T_{\mathrm{Z}}}{T}+\frac{1}{3} \\
& \times\left[Q_{\mathrm{Z}}^{2}+Q_{\mathrm{Z}}\left(Q_{\mathrm{Z}}+0.5 Q_{1}\right)+\left(Q_{\mathrm{Z}}+0.5 Q_{1}\right)^{2}\right] \frac{T_{1}}{2 T}+\frac{1}{3} \\
& \times\left[\left(Q_{\mathrm{Z}}+0.5 Q_{1}\right)^{2}-\left(Q_{\mathrm{Z}}+0.5 Q_{1}\right) 0.5 Q_{1}+\left(-0.5 Q_{1}\right)^{2}\right] \\
& \times \frac{T_{2}}{T}+\frac{1}{3}\left(-0.5 Q_{1}\right)^{2} \frac{T_{1}}{2 T}+\frac{1}{3}(0.5 D)^{2} \frac{\left(T_{1}+T_{2}\right)}{T} \\
F_{7212}^{2}= & \frac{1}{3} Q_{\mathrm{Z}}^{2} \frac{T_{\mathrm{Z}}}{T}+\frac{1}{3} \\
& \times\left[Q_{\mathrm{Z}}^{2}+Q_{\mathrm{Z}}\left(Q_{\mathrm{Z}}+0.5 Q_{2}\right)+\left(Q_{\mathrm{Z}}+0.5 Q_{2}\right)^{2}\right] \frac{T_{2}}{2 T}+\frac{1}{3} \\
& \times\left[\left(Q_{\mathrm{Z}}+0.5 Q_{2}\right)^{2}-\left(Q_{\mathrm{Z}}+0.5 Q_{2}\right) 0.5 Q_{2}+\left(-0.5 Q_{2}\right)^{2}\right] \\
& \times \frac{T_{1}}{T}+\frac{1}{3}\left(-0.5 Q_{2}\right)^{2} \frac{T_{2}}{2 T}+\frac{1}{3}(0.5 D)^{2} \frac{\left(T_{1}+T_{2}\right)}{T} \\
& \times \frac{1}{2}\left[0.5 Q_{1}\right]^{2} \frac{T_{1}}{2 T}+\frac{1}{3} \\
& \times\left[\left(0.5 Q_{1}\right)^{2}+0.5 Q_{1}\left(0.5 Q_{1}+Q_{\mathrm{Z}}\right)+\left(0.5 Q_{1}+Q_{\mathrm{Z}}\right)^{2}\right] \\
& \frac{T_{z}}{T}+\frac{1}{3}\left[\left(0.5 Q_{1}+Q_{\mathrm{Z}}\right)^{2}-\left(0.5 Q_{1}+Q_{\mathrm{Z}}\right) Q_{2}+\left(-Q_{2}\right)^{2}\right] \\
& \\
F_{1012}= & \left(-Q_{2}\right)^{2} \frac{T_{2}}{T}+\frac{1}{3}(0.5 D)^{2} \frac{T_{1}}{2 T}+(0.5 D)^{2} \\
& \\
&
\end{aligned}
$$

$$
\begin{aligned}
F_{2721}^{2}= & \frac{1}{3}\left[0.5 Q_{2}\right]^{2} \frac{T_{2}}{2 T}+\frac{1}{3} \\
& \times\left[\left(0.5 Q_{2}\right)^{2}+0.5 Q_{2}\left(0.5 Q_{2}+Q_{\mathrm{Z}}\right)+\left(0.5 Q_{2}+Q_{\mathrm{Z}}\right)^{2}\right] \\
& \times \frac{T_{z}}{T}+\frac{1}{3}\left[\left(0.5 Q_{2}+Q_{\mathrm{Z}}\right)^{2}-\left(0.5 Q_{2}+Q_{\mathrm{Z}}\right) Q_{1}+\left(-Q_{1}\right)^{2}\right] \\
& \times \frac{T_{2}}{2 T}+\frac{1}{3}\left(-Q_{1}\right)^{2} \frac{T_{1}}{T}+\frac{1}{3}(-0.5 D)^{2} \frac{T_{2}}{2 T}+(-0.5 D)^{2} \\
& \times \frac{T_{z}}{T}+\frac{1}{3}\left[(-0.5 D)^{2}+(-0.5 D)(-D)+(-D)^{2}\right] \\
& \times \frac{T_{2}}{2 T}+\frac{1}{3} D^{2} \frac{T_{1}}{T}
\end{aligned}
$$

Clearly, the rms stator flux ripple over a subcycle depends on the reference vector and the switching sequence employed. Further studies in this regard are presented in the following sections. 


\section{B. Dependence of Current Ripple on Reference Vector}

In the rms stator flux ripple expressions in (4), replacing $\alpha$ by $\left(60^{\circ}-\alpha\right)$ is equivalent to interchanging of $T_{1}$ and $T_{2}$ and that of $Q_{1}$ and $Q_{2}$. It can be seen that such a swapping leaves the RHS of (4a), namely the expression for $F_{0127}$, unchanged. This means that sequence 0127 leads to equal rms ripple at $\alpha$ and $\left(60^{\circ}-\alpha\right)$ for a given reference vector magnitude and subcycle duration as shown in

$$
F_{0127}(\alpha)=F_{0127}\left(60^{\circ}-\alpha\right) .
$$

However, the rms ripple over a subcycle is not symmetric about the center of the sector for the other sequences. Swapping of $T_{1}$ and $T_{2}$ and that of $Q_{1}$ and $Q_{2}$ in the expressions for $F_{012}$, $F_{0121}$, and $F_{1012}$, respectively, lead to the expressions for $F_{721}$, $F_{7212}$, and $F_{2721}$ as seen from (4), hence the observations in (6) regarding the rms ripple over a subcycle due to these sequences. For a given magnitude of reference vector and subcycle duration, sequences 012 and 721 yield equal rms ripple at angles $\alpha$ and $\left(60^{\circ}-\alpha\right)$, respectively, as shown in $(6 a)$. The same is true with sequences 0121 and 7212, and also with 1012 and 2721. These are shown in (6b) and (6c), respectively

$$
\begin{gathered}
F_{012}(\alpha)=F_{721}\left(60^{\circ}-\alpha\right) \\
F_{0121}(\alpha)=F_{7212}\left(60^{\circ}-\alpha\right) \\
F_{1012}(\alpha)=F_{2721}\left(60^{\circ}-\alpha\right) .
\end{gathered}
$$

Fig. 6(a) presents the variation of $F_{0127}, F_{012}, F_{0121}$, and $F_{1012}$ with the spatial angle $\alpha$ at a constant $V_{\mathrm{REF}}$ of 0.866 . As must be expected, the plot of $F_{0127}$ is symmetric about $\alpha=30^{\circ}$. However, the plots of $F_{012}, F_{0121}$, and $F_{1012}$ are not symmetric about the center of the sector. Reflecting these three curves about $\alpha=30^{\circ}$ yields the plots of $F_{721}, F_{7212}$, and $F_{2721}$, respectively. For all sequences, the rms ripple over a subcycle has its maximum at $\alpha=30^{\circ}$. With the exception of 0121 (and 7212), the rms ripple over a subcycle is low close to $\alpha=0^{\circ}$ and $\alpha=60^{\circ}$.

If the reference vector is equal to one of the voltage vectors of the inverter (say $\mathbf{V}_{1}$ ), there is no instantaneous error between the applied vector and the reference vector. Hence, the current ripple is zero during the subcycle. For $V_{\mathrm{REF}}=0.866$, the reference vector is close to $\mathbf{V}_{1}$ (or $\mathbf{V}_{2}$ ) when $\alpha$ is close to $0^{\circ}$ (or $60^{\circ}$ ). Hence, in general, the rms ripple over the subcycle is low for values of $\alpha$ close to $0^{\circ}$ and $60^{\circ}$ as seen in Fig. 6(a). As the reference vector moves closer to the center of the sector, the rms ripple increases. At $\alpha=30^{\circ}$ when the reference vector is equidistant from both $\mathbf{V}_{1}$ and $\mathbf{V}_{2}$, the rms ripple has its peak as seen from Fig. 6(a).

Fig. 6(b) and (c) present the variation of $F_{0127}, F_{012}, F_{0121}$, and $F_{1012}$ with the reference magnitude $V_{\mathrm{REF}}$ at $\alpha=30^{\circ}$ and $\alpha=5^{\circ}$, respectively. When $V_{\mathrm{REF}}=0$, the zero vector is applied over the entire subcycle; the instantaneous error voltage is zero and the rms stator flux ripple is also zero. As $V_{\mathrm{REF}}$ increases, the rms ripple also increases, in general, as seen from Fig. 6(b) and (c). Usually, the rms ripple peaks at some intermediate value of $V_{\mathrm{REF}}$, and starts decreasing thereafter.

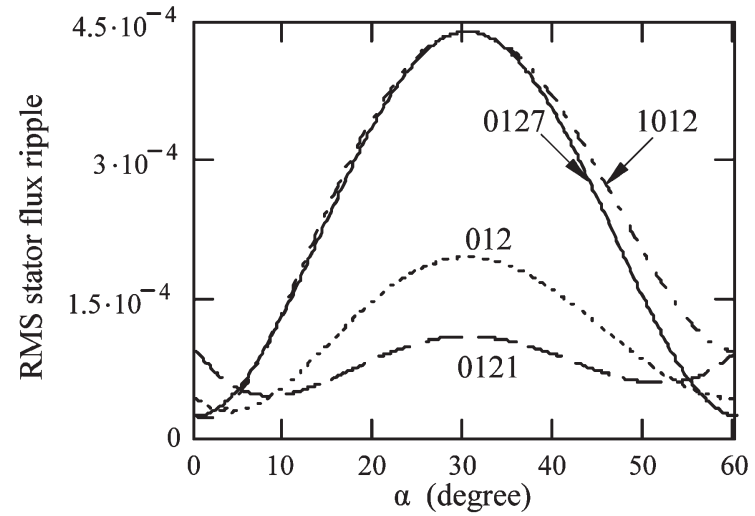

(a)

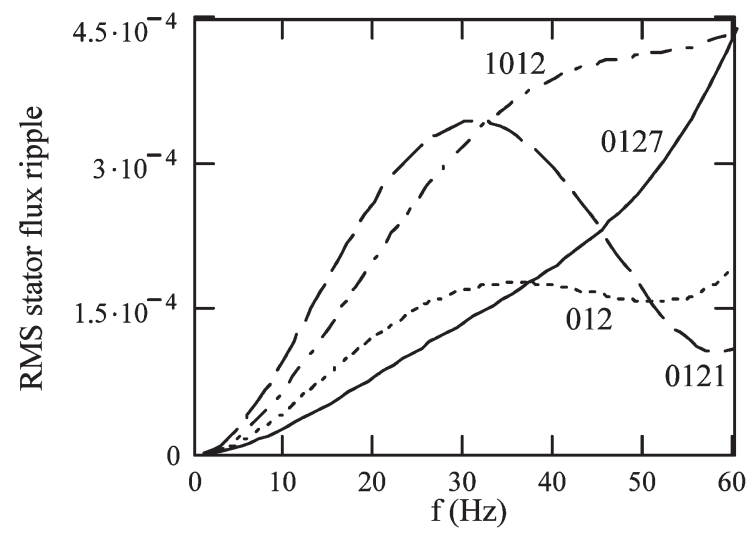

(b)

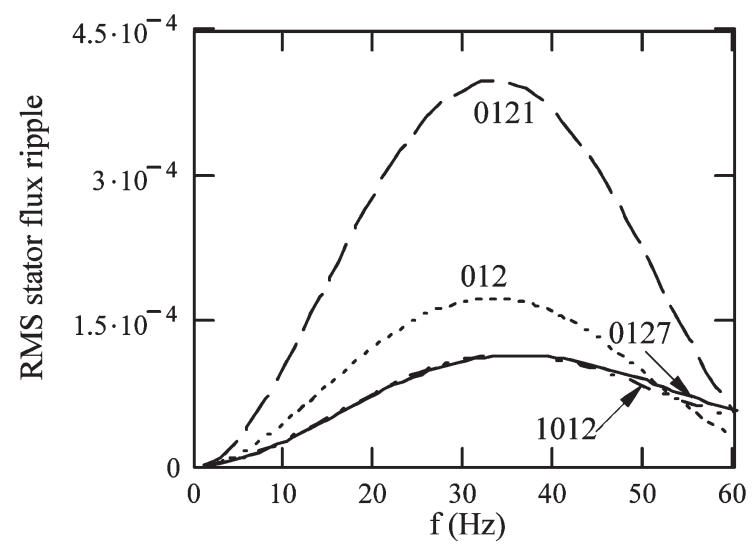

(c)

Fig. 6. Comparison of rms stator flux ripple due to 0127, 012, 0121, and 1012 for (a) $V_{\mathrm{REF}}=0.866,0^{\circ} \leq \alpha \leq 60^{\circ}$, (b) $\alpha=30^{\circ}, 0 \leq V_{\mathrm{REF}} \leq 0.866$ (c) $\alpha=5^{\circ}, 0 \leq V_{\mathrm{REF}} \leq 0.866$.

[Notable exceptions are $F_{0127}$ and $F_{1012}$ at $\alpha=30^{\circ}$, which increase monotonically till $V_{\mathrm{REF}}=0.866$ as seen in Fig. 6(b).] For $\alpha=0^{\circ}$ (or $60^{\circ}$ ), the rms ripple over a subcycle peaks at $V_{\mathrm{REF}}=0.5$, equidistant between the zero vector and $\mathbf{V}_{1}$ (or between the zero vector and $\mathbf{V}_{2}$ ), and falls back to zero at $V_{\mathrm{REF}}=1$.

\section{Dependence of Current Ripple on Switching Sequence}

Apart from the magnitude and angle of the reference vector, the rms stator flux ripple or the rms current ripple over a 
subcycle strongly depends on the switching sequence employed in the given subcycle.

1) Choice of Zero State: Barring the conventional sequence 0127, all other sequences considered employ only one zero state. The influence of the choice of the zero state used on the rms current ripple over a subcycle is studied here.

For a given reference vector, the rms $d$-axis stator flux ripple over a subcycle is equal for sequences 012 and 721 as seen from Fig. 5(b) and (c) [18], [23]. Similarly, the rms $d$-axis ripple over a subcycle is equal for sequences 0121 and 7212 as seen from Fig. 5(d) and (e) [18], [23]. Now, Fig. 5(f) and (g) show that the rms $d$-axis ripple is equal for sequences 1012 and 2721 as well.

Thus, given the reference vector and the type of sequence (say special sequence type I), the rms $d$-axis ripple over a subcycle is independent of the choice of the zero state used. In case of sequence 0127 , the rms $d$-axis ripple is independent of the ratio of apportioning of $T_{\mathrm{Z}}$ between the two zero states. However, the choice of zero state strongly influences the rms $q$-axis ripple over the subcycle as seen from Fig. 5.

When zero vector is applied, the slope of the $q$-axis stator flux ripple with time is always negative $\left(-V_{\mathrm{REF}}\right)$. When vector $\mathbf{V}_{1}$ is applied, the corresponding slope is $\left[\cos (\alpha)-V_{\mathrm{REF}}\right]$, which is nonnegative in the first half of sector I $\left(0^{\circ}<\alpha<30^{\circ}\right)$. When the applied vector is $\mathbf{V}_{2}$, the slope of the $q$-axis ripple is $\left[\cos \left(60^{\circ}-\alpha\right)-V_{\mathrm{REF}}\right]$. This could be either positive or negative in the first half of sector I depending on the relative values of $\cos \left(60^{\circ}-\alpha\right)$ and $V_{\mathrm{REF}}$. When this slope is positive, it is still less than that corresponding to $\mathbf{V}_{1}$ since $\cos (\alpha)$ is greater than $\cos \left(60^{\circ}-\alpha\right)$ in the first half of the sector.

The effect of application of zero vector on $q$-axis ripple is to increase it along the negative direction. In the interest of reducing the rms $q$-axis ripple, the next vector (or the preceding vector) applied must have the effect of increasing the $q$-axis ripple in the positive direction. Hence, from the foregoing discussion, the active vector $\mathbf{V}_{1}$ must precede or succeed the zero vector in a subcycle in the first half of sector I. This means the zero vector must be applied using the zero state $0(---)$, which is closer to the active state $1(+--)$ than the other zero state $7(+++)$. Hence, sequences 012, 0121, and 1012 lead to less rms $q$-axis ripple (and thereby less total rms ripple) than sequences 721,7212 , and 2721, respectively, in the first half of sector I as shown in (7a). Conversely, sequences 721, 7212, and 2127 lead to reduced rms ripple in the second half of sector I as shown in

$$
\begin{aligned}
& F_{012}(\alpha)<F_{721}(\alpha), \quad F_{0121}(\alpha)<F_{7212}(\alpha), \quad F_{1012}(\alpha)<F_{2721}(\alpha) \\
& \text { if } 0^{\circ}<\alpha<30^{\circ} \\
& F_{012}(\alpha)>F_{721}(\alpha), \quad F_{0121}(\alpha)>F_{7212}(\alpha), \quad F_{1012}(\alpha)>F_{2721}(\alpha) \\
& \text { if } 30^{\circ}<\alpha<60^{\circ} \text {. }
\end{aligned}
$$

2) Division of Active Vector Time: Sequences 0121, 7212, 1012, and 2721 double switch a particular phase or divide an active vector time. Such application of an active vector twice in a subcycle or division of active vector time is not possible with the triangle-comparison approach to PWM [17]. The effect of this division of active vector time on the rms stator flux ripple is studied here.
Sequences 0121 and 7212 reduce the zero-peak $d$-axis ripple by $50 \%$. Consequently, these sequences reduce the rms $d$-axis ripple by $50 \%$. These sequences are effective when the $d$-axis ripple dominates over the $q$-axis ripple.

Note that $q$-axis is parallel to the error vector $\mathbf{V}_{\mathbf{E R R}, \mathbf{Z}}$, and the $d$-axis is perpendicular to it. Sequences 0121 and 7212 reduce the rms ripple in the direction perpendicular to $\mathbf{V}_{\mathbf{E R R}, \mathbf{Z}}$.

Now, for the purpose of analysis, the stator flux ripple vector can be considered to be resolved along $\mathbf{V}_{\mathbf{E R R}, 2}$ and in a direction perpendicular to it. Sequence 1012 reduces the zeropeak ripple in the direction perpendicular to $\mathbf{V}_{\mathbf{E R R}, 2}$ by half. Consequently, the rms value of the ripple component along this direction is reduced to half. This sequence is advantageous when active vector $\mathbf{V}_{2}$ is applied only for a short duration, namely when the reference vector is proximal to $\mathbf{V}_{1}$.

Sequence 2721 reduces the rms value of the ripple component along the direction perpendicular to $\mathbf{V}_{\mathbf{E R R}, \mathbf{1}}$. By symmetry, this sequence is advantageous when $T_{1}$ is short, namely when the reference vector is close to $\mathbf{V}_{2}$.

Sequences 0121 and 012 lead to less current ripple in the middle of the sector, while 0127 and 1012 lead to less ripple close to $\alpha=0^{\circ}$. From Fig. 6(a), the sequence leading to the lowest current ripple is different in different ranges of $\alpha$ for $V_{\mathrm{REF}}=0.866$. Fig. 6(b) and (c) show that the sequence, leading to the lowest rms current ripple, changes with $V_{\mathrm{REF}}$.

Fig. 6 gives some general indications toward the regions of superior performance of the different sequences. Sequence 0121 is good at high values of $V_{\mathrm{REF}}$, particularly when $\alpha$ is close to $30^{\circ}$. This applies to 7212 as well. Sequence 1012 is well suited for values of $\alpha$ close to $0^{\circ}$. This implies that 2721 is useful close to $\alpha=60^{\circ}$. Further analysis of the relative performance of the different sequences and design of hybrid PWM techniques are presented in the following section.

\section{Proposed Hybrid PWM Techniques}

From the foregoing discussion it is clear that the best sequence (in terms of current ripple) to be employed in a subcycle has to be decided based on both the magnitude and angle of the sampled reference vector provided. A hybrid PWM technique considers a set of sequences, and employs the best one for the given reference vector. Some preliminary results on such hybrid PWM methods have been presented in [21] and [22]. Detailed results and analysis are presented here.

\section{A. Proposed Three-Zone Hybrid PWM}

The proposed three-zone hybrid PWM considers sequences 0127, 0121, and 7212. Sequences 0121 and 7212 are used in conjunction with 0127 to design a hybrid PWM, which reduces harmonic distortion over CSVPWM at a given average switching and sampling frequency.

Due to symmetries discussed in Section III, only sequences 0127 and 0121 need be compared for rms current ripple. Further it is sufficient if the comparison is restricted to the first half of sector I. The comparison is made using (4a) and (4d). As a result, sector I can be divided into three spatial regions as shown in Fig. 7(a) [21], [22]. The appropriate switching sequence is 


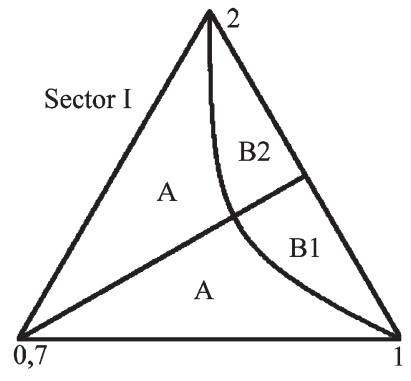

(a)

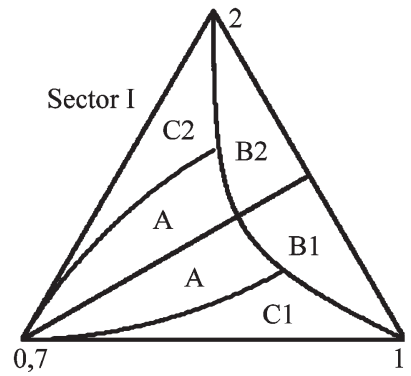

(b)

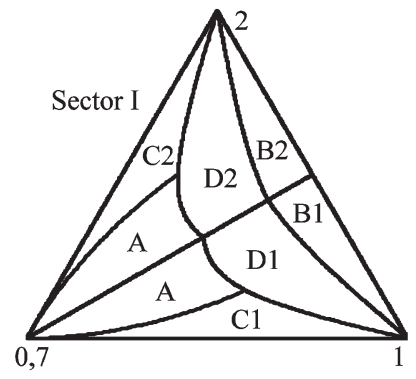

(c)

Fig. 7. Proposed hybrid PWM techniques (a) three-zone hybrid PWM, (b) five-zone hybrid PWM and (c) seven-zone hybrid PWM. The spatial regions A, B1, B2, C1, C2, D1, and D2 are the regions of superior performance of sequences 0127, 0121, 7212, 1012, 2721, 012, and 721, respectively.

chosen depending on the region in which the tip of the reference vector falls. Sequences $0127,7210, \ldots$ are used in region $\mathrm{A}$ in Fig. 7(a). Sequences $0121,1210, \ldots$ are employed in region B1, while $7212,2127, \ldots$ are used in region B2 in the figure.

\section{B. Proposed Five-Zone Hybrid PWM}

Sequences 1012 and 2721 can also be employed in addition to 0127, 0121, and 7212. Sequences 0127, 0121, and 1012 are compared in terms of rms ripple for $\alpha \leq 30^{\circ}$ using (4a), (4d) and (4f). The comparison yields the regions of superior performances of the five sequences as shown in Fig. 7(b) [22]. Sequences $1012,2101, \ldots$ are used in region C1, while 2721, $1272, \ldots$ are employed in region $\mathrm{C} 2$ in Fig. 7(b). Compared to Fig. 7(a), the size of the region A, where 0127 is employed, is reduced in Fig. 7(b).

\section{Proposed Seven-Zone Hybrid PWM}

Existing bus-clamping PWM techniques or discontinuous modulation methods employ sequences 012 and 721. A modulation method, which clamps every phase during the middle $30^{\circ}$ duration of every quarter cycle of its fundamental voltage, results in the lowest harmonic distortion among discontinuous modulation methods [1]-[9]. This is termed as " $30^{\circ}$ clamp" here. This employs sequences $012,210, \ldots$ in the first half and $721,127, \ldots$ in the second half of sector I [17], [18], [23].

A combination of sequences 0127,012 , and 721 can be employed for good harmonic performance. The regions of superior performance of the sequences can be determined by comparing (4a) and (4b). Such a hybrid PWM is very similar to the one proposed by Ogasawara et al. [4]. In addition to the switching sequence employed, the sampling period or the subcycle duration $T_{\mathrm{S}}$ also now changes with the spatial region in which the tip of the reference vector falls. The subcycle duration $T_{\mathrm{S}}=1 / 2 f_{\mathrm{sw}}$ in the region where 0127 is employed, while $T_{\mathrm{S}}=1 / 3 f_{\mathrm{sw}}$ in regions where 012 and 721 are used. Thus, this technique involves a twin sampling rate for a given average switching frequency $f_{\mathrm{sw}}$.

A hybrid PWM technique, which employs all seven sequences, can be designed along the lines explained earlier. The proposed seven-zone hybrid PWM is illustrated in Fig. 7(c) [22]. In addition to the sequences used in the five-zone hybrid PWM, sequences $012,210, \ldots$ and sequences $721,127, \ldots$, respectively, are used in regions D1 and D2 in Fig. 7(c).
When sequences 0127,012 , and 721 only are used, the PWM generation can be viewed as a process of modulation of suitable three-phase reference waves against a high frequency triangular carrier (with carrier cycle $=2 T_{\mathrm{S}}$ ) as widely discussed in the literature [3]-[11], [24], [25]. However, when special sequences are employed as with the proposed hybrid PWM techniques, the PWM waveforms are not and cannot be viewed as products of double-edged modulation of appropriate modulating waves [17]. Double switching of a phase or multiple application of an active state or division of active vector time in a subcycle is an additional degree of freedom available with space vector approach to PWM, and not possible with a triangle-comparison based approach [17]. The reduction in harmonic distortion achieved using the special sequences by the proposed hybrid PWM methods is a benefit of this flexibility of the space vector approach. The reduction in line current THD due to the proposed techniques is assessed quantitatively in the following sections.

\section{ANALYSIS OF HARMONIC DISTORTION}

A theoretical comparison of line current ripple due to different PWM techniques is presented in Fig. 8 for $V_{\mathrm{REF}}=$ 0.722 , dc bus voltage $V_{\mathrm{dc}}=294 \mathrm{~V}$, fundamental frequency $f_{1}=50 \mathrm{~Hz}$ and average switching frequency $f_{\mathrm{sw}}=1.5 \mathrm{kHz}$ with the inverter feeding a $2 \mathrm{hp}, 208 \mathrm{~V}, 60 \mathrm{~Hz}$, three-phase induction motor. The switches are considered to be ideal. It is assumed that the machine is seen as its total leakage inductance by the harmonic voltages. The total leakage inductance here is $7 \mathrm{mH}$. As seen the proposed hybrid PWM techniques lead to reduced rms line current ripple, compared to CSVPWM.

The total rms line current ripple over the entire range of modulation can be compared using the total rms harmonic distortion factor based on the notion of stator flux ripple $\left(F_{\text {DIST }}\right)$, which is independent of machine parameters. The distortion factor $F_{\text {DIST }}$ is the rms stator flux ripple over a sector, normalized with respect to the fundamental flux $\Psi_{1}$, as defined in (8) [18], [23].

$$
\begin{aligned}
F_{\text {DIST }} & =\frac{1}{\Psi_{1}} \sqrt{\frac{3}{\pi} \int_{0}^{\pi / 3} F_{\mathrm{SEQ}}^{2} d \alpha} \\
\Psi_{1} & =\frac{V_{\mathrm{REF}}}{2 \pi f_{1}} .
\end{aligned}
$$


(a)

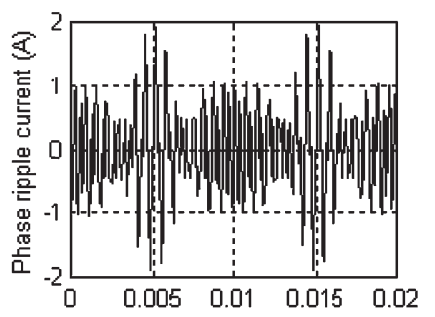

(c)

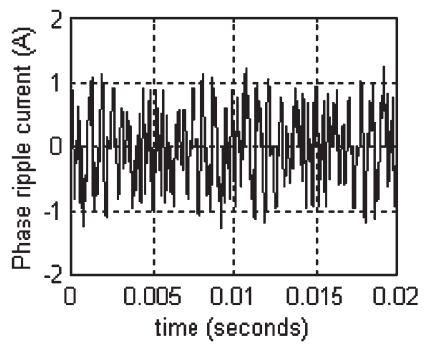

(b)

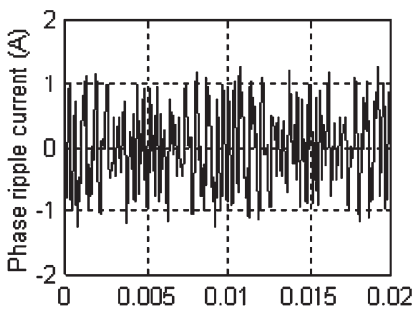

(d)

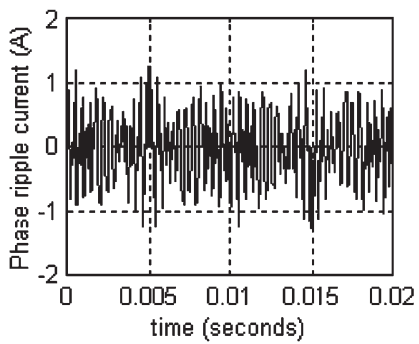

Fig. 8. Line current ripple due to (a) CSVPWM, (b) proposed three-zone hybrid PWM, (c) proposed five-zone hybrid PWM, and (d) proposed sevenzone hybrid PWM for $V_{\mathrm{REF}}=0.722, f_{1}=50 \mathrm{~Hz}$ and $f_{\mathrm{sw}}=1.5 \mathrm{kHz}$. The rms values of line current ripple are (a) $0.609 \mathrm{~A}$, (b) $0.535 \mathrm{~A}$, (c) $0.524 \mathrm{~A}$, and (d) $0.484 \mathrm{~A}$

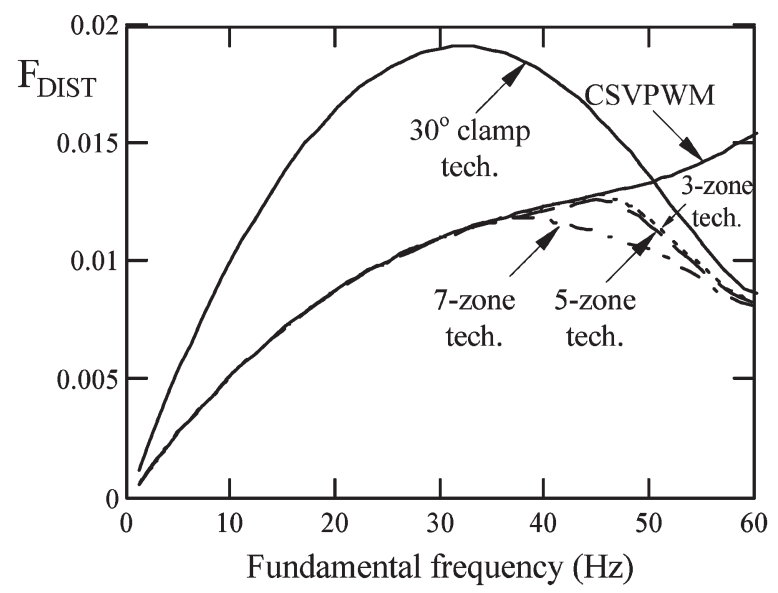

Fig. 9. Analytical evaluation of harmonic distortion due to different techniques at an average switching frequency $f_{\mathrm{sw}}=1.5 \mathrm{kHz}$.

The harmonic distortion factor is evaluated for different PWM techniques. These are shown plotted against fundamental frequency (assuming the $V / f$ ratio to be fixed at its rated value) for an average switching frequency of $1.5 \mathrm{kHz}$ and a base frequency of $60 \mathrm{~Hz}$ in Fig. 9. CSVPWM leads to low harmonic distortion at lower line voltages, while $30^{\circ}$ clamp leads to lower distortion at higher voltages. Ogasawara's hybrid PWM leads to improvement around the line voltage, where $30^{\circ}$ clamp becomes superior to CSVPWM [4]. As mentioned earlier, this technique requires a higher sampling rate in regions where sequences 012 and 721 are employed.

With the simplicity of only three sequences and uniform sampling, the proposed three-zone PWM leads to reduced distortion over CSVPWM at high speeds. The distortion is also better than any of the discontinuous modulation methods [1]-[10] close to the base speed (i.e., 50 to $60 \mathrm{~Hz}$ ).

The proposed five-zone technique leads to further reduction in the harmonic distortion. This reduction, though only marginal over three-zone PWM, is over a wider speed range. The distortion is the lowest among real-time PWM techniques with a constant sampling frequency.

The proposed seven-zone technique with a twin sampling rate leads to the lowest distortion over comparable real-time PWM techniques at any given line voltage. This particularly improves the distortion in the range 35 to $50 \mathrm{~Hz}$. The proposed techniques lead to about $40 \%$ reduction in the line current distortion over CSVPWM at the base frequency of the drive at a given average switching frequency.

\section{Analysis of DC Link CURRENT}

The inverter input current or the dc link current $i_{\mathrm{dc}}$ is of practical significance since the ripple content of it is required to determine the rms current rating of the dc link capacitor [26], [27]. The dc link current depends on the phase currents $\left(i_{\mathrm{R}}, i_{\mathrm{Y}}, i_{\mathrm{B}}\right)$ and the switching functions $\left(S_{\mathrm{R}}, S_{\mathrm{Y}}, S_{\mathrm{B}}\right)$ of the three phases as shown in (9). The function $S_{\mathrm{R}}=1$ if R-phase top device is on, and $S_{\mathrm{R}}=0$ if the bottom device is on

$$
i_{\mathrm{dc}}=S_{\mathrm{R}} i_{\mathrm{R}}+S_{\mathrm{Y}} i_{\mathrm{Y}}+S_{\mathrm{B}} i_{\mathrm{B}} .
$$

For a given $V_{\mathrm{REF}}$, the peak phase fundamental voltage is $(2 / 3)^{*} V_{\mathrm{REF}}^{*} V_{\mathrm{dc}}$. The inverter output power is $V_{\mathrm{REF}}^{*} V_{\mathrm{dc}}^{*} I_{\mathrm{m}} \cos (\phi)$. Using input-output power balance and neglecting inverter losses, the average dc link current $I_{\mathrm{dc}}$ is as given by (11). This is independent of the PWM technique

$$
I_{\mathrm{dc}}=V_{\mathrm{REF}} I_{\mathrm{m}} \cos (\phi) .
$$

The dc link current is zero when a zero state is applied. The dc link current equals $i_{\mathrm{R}}$ when active state 1 is applied, and equals $\left(i_{\mathrm{R}}+i_{\mathrm{Y}}\right)$ when active state 2 is applied. The rms dc link current over a subcycle $i_{\mathrm{dc}(\mathrm{SUB})}$ in sector I is as given in (11), where $I_{\mathrm{m}}$ is the peak value of fundamental current and $\phi$ is the power factor angle. The ripple components in the line currents have been ignored [27]. Note that $i_{\mathrm{dc}(\mathrm{SUB})}$ is independent of the switching sequence used. The rms dc link current over a sector or a fundamental cycle $i_{\mathrm{dc}(\mathrm{rms})}$ is calculated as shown in (12). As seen the rms value depends on $V_{\mathrm{REF}}, I_{\mathrm{m}}$, and $\phi$, and is independent of the PWM technique employed when the ripple current is neglected [27].

$$
\begin{aligned}
& i_{\mathrm{dc}(\mathrm{SUB})} \\
& \quad=\sqrt{I_{\mathrm{m}}^{2} \cos ^{2}(\alpha-\phi) \frac{T_{1}}{T_{\mathrm{S}}}+I_{\mathrm{m}}^{2} \cos ^{2}\left(\alpha-\phi+120^{\circ}\right) \frac{T_{2}}{T_{\mathrm{S}}}} \\
& i_{\mathrm{dc}(\mathrm{rms})} \\
& =\sqrt{\frac{3}{\pi} \int_{0}^{\pi / 3} i_{\mathrm{dc}(\mathrm{SUB})}^{2} d \alpha}=I_{\mathrm{m}} \sqrt{\frac{V_{\mathrm{REF}}}{\pi \sqrt{3}}\left(4 \cos ^{2}(\phi)+1\right)} .
\end{aligned}
$$

The dc link current waveforms corresponding to the different techniques for an rms fundamental current of $6.5 \mathrm{~A}$ and 
(a)

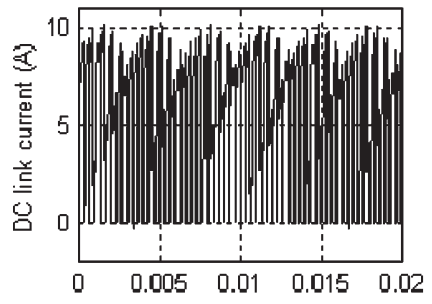

(c)

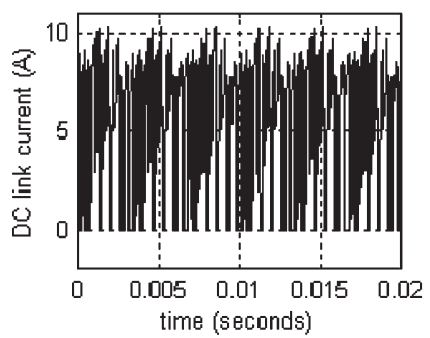

(b)

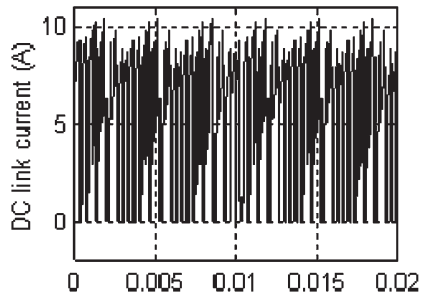

(d)

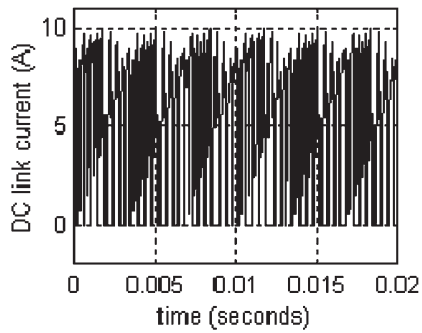

Fig. 10. DC link current corresponding to (a) CSVPWM, (b) proposed threezone hybrid PWM, (c) proposed five-zone hybrid PWM, and (d) proposed seven-zone hybrid PWM for rms fundamental current of $6.5 \mathrm{~A}$ at a power factor of 0.866 (lag). The rms values are (a) $6.694 \mathrm{~A}$, (b) $6.706 \mathrm{~A}$, (c) $6.698 \mathrm{~A}$, and (d) $6.844 \mathrm{~A}$.

$\phi=30^{\circ}$ (lag) are as shown in Fig. 10. The dc voltage, reference magnitude, and fundamental and switching frequencies are the same as in Fig. 8. These waveforms have been calculated using (9) and considering the actual phase currents which include the ripple shown in Fig. 8. The average and the rms values of the dc link current in all four cases tally well with those predicted by (10) and (12), respectively. Consequently, the rms value of the ripple current through the dc capacitor is also almost equal in all cases.

Thus, the choice of PWM technique does not significantly affect the rms ripple current through the dc capacitor, but influences the line current ripple significantly. The proposed hybrid PWM techniques reduce the line current ripple significantly at higher modulation indices as shown theoretically in Section V and experimentally in Section VII.

\section{EXPERIMENTAL INVESTIGATION}

The proposed hybrid PWM techniques are tested on a $2 \mathrm{hp}, 208 \mathrm{~V}, 60 \mathrm{~Hz}$, three-phase constant $V / f$ induction motor drive fed from a $2 \mathrm{~kW}$ Intelligent Power Module based inverter. TMS320C243 DSP-based digital controller is used as the controller platform.

Measured line voltage spectra corresponding to CSVPWM and the three proposed hybrid techniques at the rated voltage and rated frequency of the drive are presented in Fig. 11. The average switching frequency $\left(f_{\mathrm{sw}}\right)$ is $1.5 \mathrm{kHz}$. Fig. 11(a) shows that the dominant harmonic components for CSVPWM are around $1.5 \mathrm{kHz}$. However, for the proposed hybrid PWM techniques, the harmonic components around $1.5 \mathrm{kHz}$ are quite low, and the dominant harmonics are shifted to a higher frequency of around $3 \mathrm{kHz}$ as seen from Fig. 11(b)-(d).

The harmonic distortion factor of the no-load current waveform $I_{\mathrm{THD}}$ is a widely used performance measure for PWM
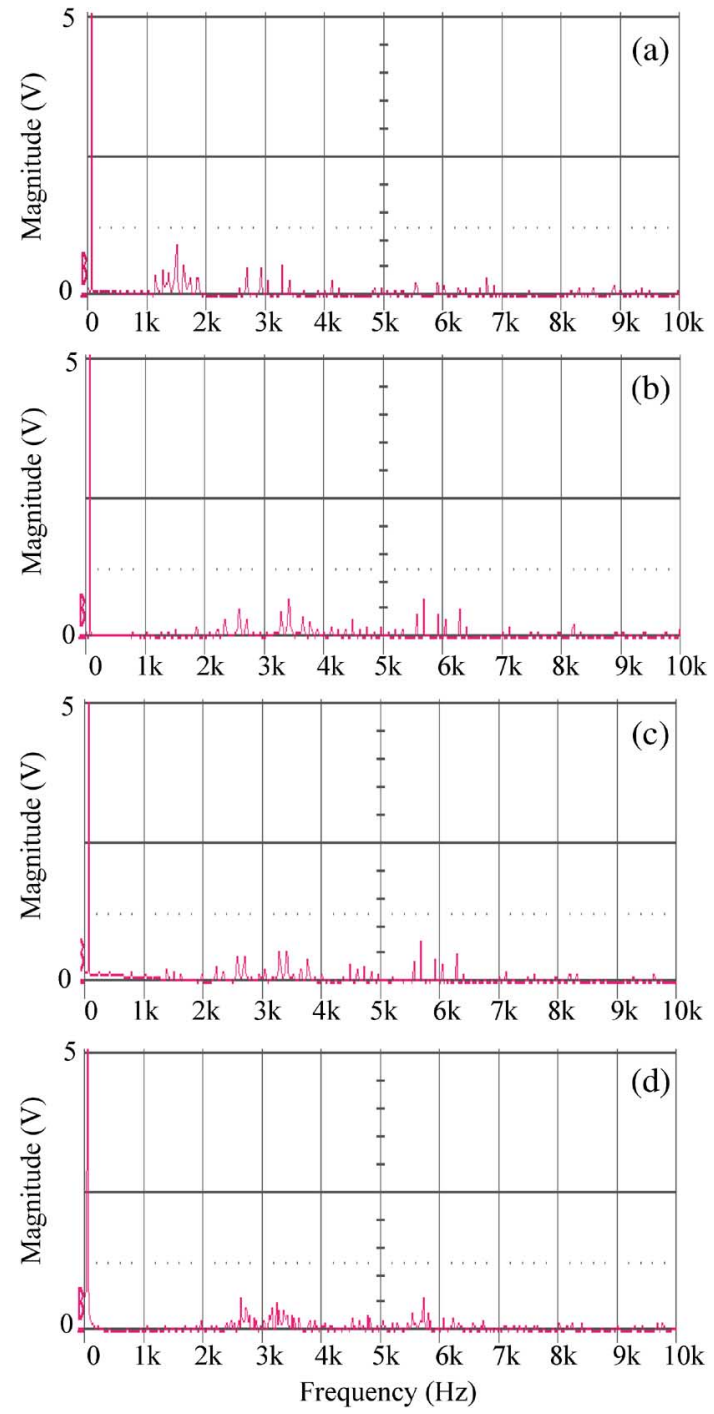

Fig. 11. Measured spectra of line voltage (PWM of R-phase minus PWM of Y-phase) at $f_{1}=60 \mathrm{~Hz}$ and $f_{\mathrm{sw}}=1.5 \mathrm{kHz}$ for (a) CSVPWM, (b) proposed three-zone hybrid PWM, (c) proposed five-zone hybrid PWM, and (d) proposed seven-zone hybrid PWM.

techniques [1], [2]. $I_{\mathrm{THD}}$ is defined in (13), where $I_{1}$ and $I_{n}$ are the rms values of the fundamental and $n$th harmonic components, respectively, of the no-load current. Measured noload current waveforms in Fig. 12 show that the proposed hybrid PWM techniques result in lower distortion than CSVPWM and $30^{\circ}$ clamp at rated voltage and rated frequency of the drive.

$$
I_{\mathrm{THD}}=\frac{1}{I_{1}} \sqrt{\sum_{n \neq 1} I_{n}^{2}} .
$$

The improvement in harmonic distortion due to the proposed techniques over CSVPWM is verified experimentally over a range of speed. The no-load $I_{\mathrm{THD}}$ is measured over a range of fundamental frequency $\left(f_{1}\right)$ from 40 to $60 \mathrm{~Hz}$ in steps of $2 \mathrm{~Hz}$, and is shown plotted for CSVPWM and the three proposed hybrid techniques in Fig. 13. The measured values agree with the theoretical prediction in Fig. 9 regarding the reduction in harmonic distortion due to the proposed PWM techniques. 

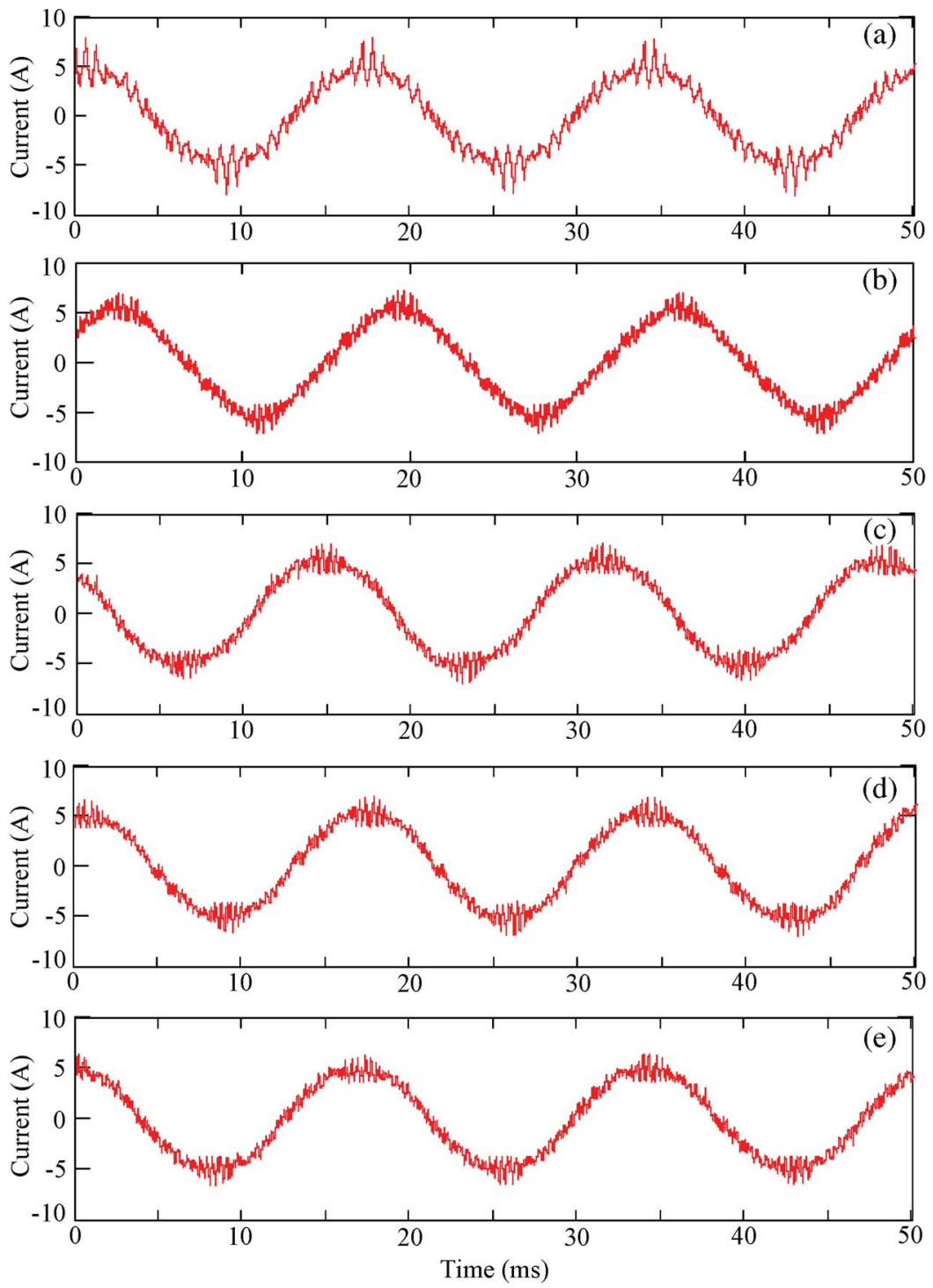

Fig. 12. Measured no-load current waveforms at $f_{1}=60 \mathrm{~Hz}$ and $f_{\mathrm{sw}}=1.5 \mathrm{kHz}$ for (a) CSVPWM, (b) $30^{\circ}$ clamp, (c) proposed three-zone hybrid PWM, (d) proposed five-zone hybrid PWM and (e) proposed seven-zone hybrid PWM. The measured $I_{\text {THD }}$ values are (a) 0.2029, (b) 0.1537, (c) 0.1300, (d) 0.1272, and (e) 0.1258 .



Fig. 13. Measured no-load THD against fundamental frequency for (a) CSVPWM, (b) proposed three-zone hybrid PWM, (c) proposed five-zone hybrid PWM, and (d) proposed seven-zone hybrid PWM.

Further experimental investigations are carried out under loaded conditions on a $2 \mathrm{hp}, 230 \mathrm{~V}, 60 \mathrm{~Hz}$, three-phase, four-
TABLE II

COMPARISON OF CSVPWM AND THREE-ZONE HYBRID PWM AT DIFFERENT LOADS AND $f_{1}=60 \mathrm{~Hz}$

\begin{tabular}{|c|c|c|c|c|}
\hline Load & Technique & $\begin{array}{c}\text { RMS } \\
\text { ripple } \\
\text { current (A) }\end{array}$ & $\begin{array}{c}\text { Current } \\
\text { THD }\end{array}$ & $\begin{array}{c}\text { Reduction in } \\
\text { THD due to } \\
\text { hybrid PWM }\end{array}$ \\
\hline \multirow{2}{*}{$\begin{array}{c}\text { No } \\
\text { load }\end{array}$} & CSVPWM & 0.286 & 0.1269 & $29.4 \%$ \\
\cline { 2 - 4 } $0.4 \mathrm{hp}$ & 3-zone hybrid & 0.201 & 0.0896 & \\
\cline { 2 - 4 } & CSVPWM & 0.375 & 0.1552 & \multirow{2}{*}{$29.7 \%$} \\
\hline \multirow{2}{*}{$1 \mathrm{hp}$} & 3-zone hybrid & 0.262 & 0.1091 & \\
\cline { 2 - 4 } & CSVPWM & 0.493 & 0.1482 & \multirow{2}{*}{$34.3 \%$} \\
\hline
\end{tabular}

pole induction motor coupled to a suitable $2 \mathrm{hp}, 180 \mathrm{~V}$, dc shunt generator for loading. Measured rms current ripple and measured current THD corresponding to CSVPWM and threezone hybrid PWM at different loads, namely no-load, $0.4 \mathrm{hp}$ load and $1 \mathrm{hp} \mathrm{load}$ are presented in Table II. The corresponding measured current waveforms at no-load and $1 \mathrm{hp}$ load are 

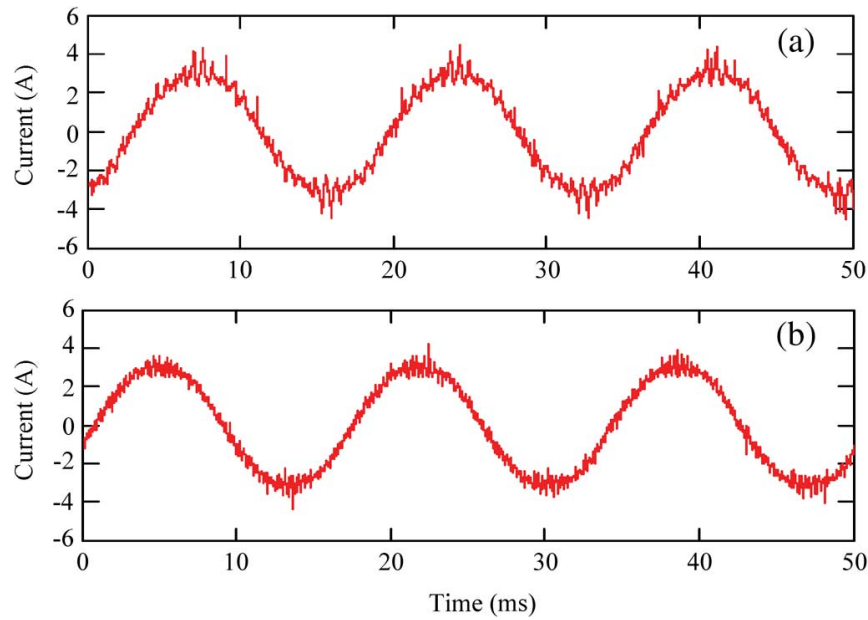

Fig. 14. Comparison of measured line current waveforms corresponding to (a) CSVPWM and (b) proposed three-zone hybrid PWM at $f_{1}=60 \mathrm{~Hz}$, $f_{\mathrm{sw}}=1.5 \mathrm{kHz}$ and no-load.
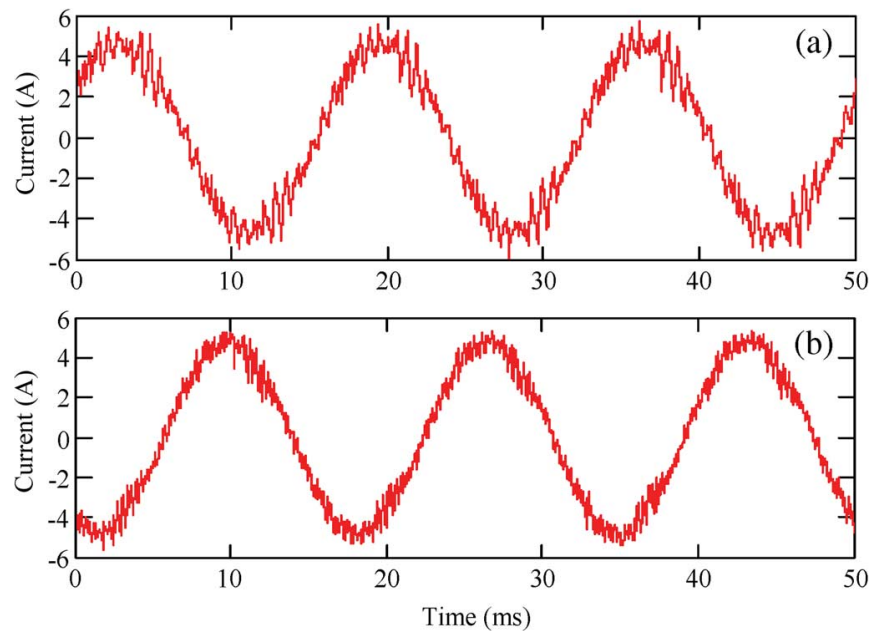

Fig. 15. Comparison of measured line current waveforms corresponding to (a) CSVPWM and (b) proposed three-zone hybrid PWM at $f_{1}=60 \mathrm{~Hz}$, $f_{\mathrm{sw}}=1.5 \mathrm{kHz}$ and $1 \mathrm{hp} \mathrm{load}$.

presented in Figs. 14 and 15, respectively. As seen the proposed technique leads to lower harmonic distortion than CSVPWM under different conditions of load.

Measured line voltage spectra corresponding to CSVPWM and the proposed three-zone hybrid PWM at $f_{1}=50 \mathrm{~Hz}$ are presented in Fig. 16(a) and (b), respectively. With CSVPWM the harmonic components are around frequencies that are integral multiples of the switching frequency. On the other hand, with the three-zone method, the spectra are more spread out. The harmonic distortion is also less than that of CSVPWM at this fundamental frequency as seen from Fig. 9. This indicates the possibility of generating spread spectrum PWM waveforms to reduce acoustic noise in motor drives [28], [29] using a judicious mixture of switching sequences. The sampling frequency does not have to be random, but could very well be uniform with all the attendant advantages. The harmonic distortion could also be less than that of CSVPWM. Further research is required in this direction.


Fig. 16. Measured spectra of line voltage (PWM of R-phase minus PWM of Y-phase) at $f_{1}=50 \mathrm{~Hz}$ and $f_{\mathrm{sw}}=1.5 \mathrm{kHz}$ for (a) CSVPWM and (b) proposed three-zone hybrid PWM.

\section{CONCLUSION}

Novel switching sequences, which can be employed in space vector based PWM generation, are brought out. Influence of the switching sequences on the rms current ripple over a subcycle is investigated. A procedure is presented for designing hybrid PWM techniques involving multiple sequences for reduced current ripple.

Three hybrid PWM techniques are proposed, namely threezone, five-zone and seven-zone hybrid PWM. The proposed five-zone hybrid PWM leads to lowest distortion in its class of PWM techniques (open-loop, real-time techniques with a uniform sampling rate) at any given modulation index for a given average switching frequency. The proposed seven-zone hybrid PWM leads to lowest distortion in its class (open-loop, real-time techniques with a twin sampling rate) at any given modulation index for a given average switching frequency. The proposed techniques lead to about $40 \%$ reduction in line current distortion over CSVPWM at the rated voltage and rated frequency of the drive. The superior performance of the proposed techniques over CSVPWM and existing bus-clamping PWM techniques has been demonstrated theoretically as well as experimentally. Spread spectrum PWM waveforms can be generated using hybrid PWM techniques with a uniform sampling frequency rather than special methods with random sampling frequency.

\section{REFERENCES}

[1] J. Holtz, "Pulsewidth modulation-A survey," IEEE Trans. Ind. Electron., vol. 39, no. 5, pp. 410-420, Dec. 1992

[2] J. Holtz, "Pulsewidth modulation for electronic power conversion," Proc. IEEE, vol. 82, no. 8, pp. 1194-1214, Aug. 1994.

[3] D. G. Holmes and T. A. Lipo, Pulse Width Modulation for Power Converters: Principles and Practice. Hoboken, NJ: Wiley, 2003. 
[4] S. Ogasawara, H. Akagi, and A. Nabae, "A novel PWM scheme of voltage source inverters based on space vector theory," in Proc. EPE, Aachen, Germany, Oct. 1989, pp. 1197-1202.

[5] J. W. Kolar, H. Ertl, and F. C. Zach, "Minimising the current harmonics RMS value of three-phase PWM converter system by optimal and suboptimal transition between continuous and discontinuous modulation," in Proc. IEEE-PESC, Jun. 1991, pp. 372-381.

[6] V. Blasko, "Analysis of a hybrid PWM based on modified space-vector and triangle-comparison methods," IEEE Trans. Ind. Appl., vol. 33, no. 3, pp. 756-764, May/Jun. 1997.

[7] S. Fukuda and K. Suzuki, "Harmonic evaluation of two-level carrier-based PWM methods," in Proc. EPE, Trondheim, Norway, 1997, pp. 331-336.

[8] A. M. Hava, R. J. Kerkman, and T. A. Lipo, "Simple analytical and graphical methods for carrier-based PWM-VSI drives," IEEE Trans. Power Electron., vol. 14, no. 1, pp. 49-61, Jan. 1999.

[9] H. W. van der Broeck, "Analysis of the harmonics in voltage fed inverter drives caused by PWM schemes with discontinuous switching operation," in Proc. EPE, Firenze, Italy, 1991, pp. 261-266.

[10] P. G. Handley and J. T. Boys, "Practical real-time PWM modulators: An assessment," Proc. Inst. Electr. Eng.-Electr. Power Appl., vol. 139, no. 2, pp. 96-102, Mar. 1992.

[11] D. Casadei, G. Serra, A. Tani, and L. Zarri, "Theoretical and experimental analysis for the RMS current ripple minimization in induction motor drives controlled by SVM technique," IEEE Trans. Ind. Electron., vol. 51, no. 5, pp. 1056-1065, Oct. 2004.

[12] M. J. Meco-Gutierez, F. Perez-Hidalgo, F. Vargas-Merino, and J. R. Heredia-Larrubia, "A new PWM technique frequency regulated carrier for induction motors supply," IEEE Trans. Ind. Electron., vol. 53, no. 5, pp. 1750-1754, Oct. 2006.

[13] R. A. Jabr, "Solution trajectories of the harmonic-elimination problem," Proc. Inst. Electr. Eng.-Electr. Power Appl., vol. 153, no. 1, pp. 97-104, Jan. 2006.

[14] V. G. Agelidis, A. Balouktsis, I. Balouktsis, and C. Cossar, "Multiple sets of solutions for harmonic elimination PWM bipolar waveforms: Analysis and experimental verification," IEEE Trans. Power Electron., vol. 21, no. 2, pp. 415-421, Mar. 2006.

[15] J. R. Wells, X. Geng, P. L. Chapman, P. T. Krein, and B. M. Nee, "Modulation-based harmonic elimination," IEEE Trans. Power Electron., vol. 22, no. 1, pp. 336-340, Jan. 2007.

[16] S. R. Bowes and D. Holliday, "Optimal regular sampled PWM inverter control techniques," IEEE Trans. Ind. Electron., vol. 54, no. 3, pp. 1547-1559, Jun. 2007.

[17] G. Narayanan, "Synchronised pulsewidth modulation strategies based on space vector approach for induction motor drives," $\mathrm{Ph} . \mathrm{D}$. dissertation, Indian Inst. Sci., Bangalore, India, Aug. 1999.

[18] G. Narayanan and V. T. Ranganathan, "Analytical evaluation of harmonic distortion in PWM AC drives using the notion of stator flux ripple," IEEE Trans. Power Electron., vol. 20, no. 2, pp. 466-474, Mar. 2005.

[19] A. R. Beig, G. Narayanan, and V. T. Ranganathan, "Modified SVPWM algorithm for three level VSI with synchronized and symmetrical waveforms," IEEE Trans. Ind. Electron., vol. 54, no. 1, pp. 486-494, Feb. 2007.

[20] S. Bernet, R. Teichmann, A. Zuckerberger, and P. K. Steimer, "Comparison of high-power IGBT's and hard-driven GTO's for high-power inverters," IEEE Trans. Ind. Appl., vol. 35, no. 2, pp. 487-495, Mar./Apr. 1999.

[21] H. Krishnamurthy, G. Narayanan, R. Ayyanar, and V. T. Ranganathan, "Design of space vector-based hybrid PWM techniques for reduced current ripple," in Proc. IEEE-APEC, Miami, FL, Feb. 2003, pp. 583-588.

[22] D. Zhao, G. Narayanan, and R. Ayyanar, "Switching loss characteristics of sequences involving active state division in space vector based PWM," in Proc. IEEE-APEC, Anaheim, CA, Feb. 2004, pp. 479-485.

[23] G. Narayanan, H. K. Krishnamurthy, D. Zhao, and R. Ayyanar, "Advanced bus-clamping PWM techniques based on space vector approach," IEEE Trans. Power Electron., vol. 21, no. 4, pp. 974-984, Jul. 2006.

[24] K. Zhou and D. Wang, "Relationship between space-vector modulation and three-phase carrier-based PWM: A comprehensive analysis," IEEE Trans. Ind. Electron., vol. 49, no. 1, pp. 186-196, Feb. 2002.

[25] A. Cataliotti, F. Genduso, A. Raciti, and G. R. Galluzzo, "Generalized PWM-VSI control algorithm based on a universal duty-cycle expression: Theoretical analysis, simulation results, and experimental validations," IEEE Trans. Ind. Electron., vol. 54, no. 3, pp. 1569-1580, Jun. 2007.

[26] P. D. Ziogas and P. N. D. Photiadis, "An exact input current analysis of ideal static PWM inverters," IEEE Trans. Ind. Appl., vol. IA-19, no. 2, pp. 281-295, Mar./Apr. 1983.

[27] J. W. Kolar and S. D. Round, "Analytical calculation of the RMS current stress on the DC-link capacitor of voltage-PWM converter systems," Proc. Inst. Electr. Eng.-Electr. Power Appl., vol. 153, no. 4, pp. 535-543, Jul. 2006.
[28] G. A. Covic and J. T. Boys, "Noise quieting with random PWM ac drives," Proc. Inst. Electr. Eng.-Electr. Power Appl., vol. 145, no. 1, pp. 1-10, Jan. 1998.

[29] A. Hirota, S. Nagai, and M. Nakaoka, "A novel delta-sigma modulated space vector modulation scheme using scalar delta-sigma modulators," in Proc. IEEE-PESC, 2003, pp. 485-489.

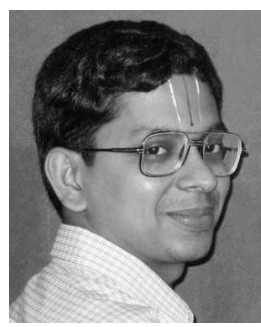

G. Narayanan (S'99-M'01) received the B.E. degree from Anna University, Tamil Nadu, India, in 1992, and the M.Tech. degree from the Indian Institute of Technology, Kharagpur, India, in 1994. He received the Ph.D. degree from the Indian Institute of Science, Bangalore, India, in 2000.

$\mathrm{He}$ is currently an Assistant Professor in the Department of Electrical Engineering, Indian Institute of Science. His research interests include ac drives, pulsewidth modulation, multilevel inverters, and protection of power devices.

Dr. Narayanan received the Innovative Student Project Award for his Ph.D. work from the Indian National Academy of Engineering in 2000, and the Young Scientist Award from the Indian National Science Academy in 2003.

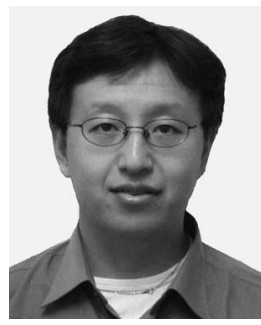

Di Zhao received the M.S. degree from Tsinghua University, Beijing, China, and the Ph.D. degree from Arizona State University, Tempe.

He has been a Design Engineer at Texas Instruments, Dallas, since October 2006. His research interests include topologies and control techniques for switch mode power converters, new pulsewidth modulation techniques for drives, and integrated power management for radio frequency application.

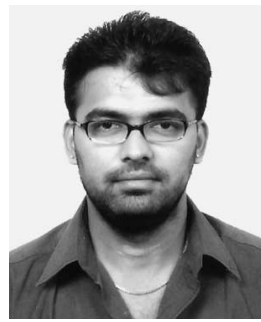

Harish K. Krishnamurthy received the M.S. degree in electrical engineering from the Arizona State University, Tempe. He is currently working toward his $\mathrm{Ph} . \mathrm{D}$. degree in electrical engineering at the Arizona State University.

His research interests include topologies and control techniques for switch mode power converters and new pulsewidth modulation techniques for drives. 


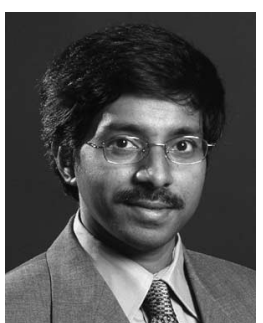

Rajapandian Ayyanar (S'97-M'00-SM'06) received the M.S. degree from the Indian Institute of Science, Bangalore, India, and the Ph.D. degree from the University of Minnesota, Minneapolis.

$\mathrm{He}$ is presently an Associate Professor at Arizona State University, Tempe. He has many years of industrial experience designing switch mode power supplies. His current research interests include topologies and control techniques for switch mode power converters, especially dc-dc converters, fully modular power system architecture, new pulsewidth modulation techniques for drives, distributed generation, renewable energy interface, and other power electronic applications in power systems.

Dr. Ayyanar received an Office of Naval Research Young Investigator Award in 2005

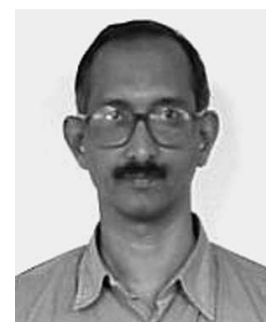

V. T. Ranganathan (M'86-SM'95) received the B.E. and M.E. degrees in electrical engineering from the Indian Institute of Science, Bangalore, India, and the Ph.D. degree from Concordia University, Montreal, Canada.

He joined the Electrical Engineering Department at Indian Institute of Science in 1984 and is currently a Professor. His research interests are in the area of Power Electronics and Motor Drives. He has published several papers in the areas of vector control of ac drives, pulsewidth modulation techniques, split phase induction motor drives, control of wound rotor induction machines for wind energy applications, double inverter fed wound rotor induction motor drives and three level inverters for ac motor drives. He is also a Consultant to industry in the above areas and has participated in a number of projects.

Dr. Ranganathan has been a recipient of the Prize paper Award of the IEEEIAS Static Power Converter Committee, The Tata Rao Prize of the Institution of Engineers, India, The VASVIK Award, The Bimal Bose Award of The Institution of Electronic and Telecommunication Engineers and The C. V. Raman Young Scientist Award of the Government of Karnataka. He received the Rustom Choksi Award for Excellence in Engineering Research (2005) of The Indian Institute of Science. He is a Fellow of The Indian National Academy of Engineering, Fellow of the Institution of Engineers, India. 